\title{
MAPEAMENTO DO PROGRESSO DE MOLDES - UMA FERRAMENTA DE GESTÃO VISUAL PARA A INDÚSTRIA 4.0
}

1 Erising, Cascais, Portugal

\author{
D. P. Jorge ${ }^{1 *}$, P. Peças ${ }^{2}$
}

2 IDMEC, Instituto Superior Técnico, Universidade de Lisboa, Av. Rovisco Pais, 1049-001, Lisboa, Portugal

*diogojorge@erising.pt

Artigo submetido em 23/10/2017 e aceito em 15/01/2018

\section{RESUMO}

O planeamento da produção de moldes é uma tarefa muito complexa para a qual os métodos clássicos têm tido um sucesso limitado, devido às especificidades da produção de moldes: o molde "explode" em múltiplos componentes; cada molde é único e são frequentes as alterações ao design do molde solicitadas pelos clientes. Neste artigo é proposta uma metodologia de Mapeamento do Progresso dos Moldes (MPM) baseada no conhecimento dos autores das práticas vigentes em diversas empresas fabricantes de moldes, nas lógicas de Produção Enxuta (Lean Manufacturing) e de Gestão Visual, e ainda nas tendências atuais de sensorização e digitalização de processos tendo em vista a perspetiva da Indústria 4.0. O MPM permite saber a cada momento qual o progresso global do fabrico, qual o desvio relativamente ao planeado e qual o diferencial para o prazo de entrega. Exige "apenas" que o decisor indique ao MPM a criticidade dos tipos de componentes do molde e a contribuição prevista das fases de fabrico. Requer ainda que os processos e as tarefas estejam digitalizados e que a informação sejam centralizada no sistema de informação da empresa. O MPM pode também ser usado noutros sistemas de produção complexas.

\section{MOLDS PRODUCTION PROGRESS MAPPING - A VISUAL MANAGEMENT TOOL FOR THE INDUSTRY 4.0}

\begin{abstract}
The planning of injection molds production is a complex task where the classic planning approaches has proven limitations because of the following particular characteristics: the mold expands in a myriad of components for production; the "one-of-a-kind" type of production and recurrent mold design changes asked by the customer. To overcome this challenge a methodology to Molds Production progress Mapping is proposed (MPM). The methodology was built on the authors experience in collaborating with mold making companies, on the principles of lean manufacturing and visual management (VM) and also have in mind the trend
\end{abstract}

towards production digitalization to be aligned with Industry 4.0 evolution. As a VM tool to support molds production planning, the MPM shows the instant progress of each mold, the deviation from planning and the remaining time for the due date. The user has "only" to input the mold's components critic level and the relative weight of each production process in the total time; it also requires that the production process are armed with sensors and the production task are digitalized and compiled in the information management system. The MPM can also be used in other complex production systems.

KEYWORDS: molds production, production planning, process mapping, visual management, industry 4.0 


\section{INTRODUÇÃO}

À semelhança de outros setores industriais, o setor do fabrico de moldes para injeção de plástico enfrenta a necessidade de ultrapassar vários desafios em simultâneo. A estratégia específica adotada por cada empresa para ultrapassar estes desafios depende essencialmente da localização geográfica, do seu nível de conhecimento de engenharia de projeto e de produção de moldes, e do seu nível tecnológico (equipamentos e domínio do conhecimento sobre os mesmos) (WEF, 2016; Henriques, Peças, 2004). A maioria dos fabricantes de moldes em Portugal está numa posição similar aos seus congéneres Europeus, Norte Americanos e Japoneses (Henriques, Peças, 2004; Henriques, Peças, 2012). Caracterizam-se em geral por possuírem elevados padrões tecnológicos, elevados conhecimentos de engenharia e um elevado desempenho em termos da qualidade global do molde e do serviço ao cliente. Os desafios para estas empresas consistem em permanecerem neste patamar de excelência e em simultâneo responderem a um mercado cada vez mais exigente em termos de complexidade dos moldes, de tempos de entrega cada vez mais curtos e duma permanente e crescente preocupação ambiental, consubstanciada na minimização de desperdícios (WEF, 2016; Henriques, Peças, 2012; Henriques, Peças, 2015; Henriques, Peças, 2003). Têm ainda de conviver com uma permanente pressão de fabricantes asiáticos, obrigando a uma permanente vigília dos custos de produção e logísticos. Daqui resulta uma necessidade de redução de desperdícios e de tempo sem valor acrescentado, onde a maximização da eficiência de utilização dos recursos de elevado nível tecnológico é um fator chave e diferenciador (WEF, 2016; Henriques, Peças, 2012; Wongwiwat et al., 2013).

Neste artigo foca-se essencialmente o aspeto da redução dos desperdícios temporais e de recursos (operador e equipamento) através do contributo para um planeamento da produção mais consciente e maximizando o fluxo dos componentes.

O planeamento do fabrico de moldes é uma tarefa extremamente complexa por diversos fatores. O primeiro desses fatores é o facto de as empresas estarem, em geral, dimensionadas para produzir duas a quatro dezenas de moldes por ano. Sendo que cada molde tem um tempo de produção que pode variar, em geral, entre 15 e 30 semanas, significa que estão em produção em simultâneo entre 10 a 20 moldes. Considerando que os moldes têm várias dezenas de componentes o problema torna-se extremamente complexo em termos de decisões de escalonamento, priorização e sequência de produção (Wongwiwat et al., 2013; Florjanič, Kuzman, 2012; Apostu, Bendul, 2015). O segundo destes fatores está relacionado com a tipologia de produtos que se pode considerar como "one-of-a-kind", ou seja, cada molde (e, portanto, as suas largas dezenas de componentes) são em geral diferentes de todos os outros produzidos até essa data. Mais uma vez a complexidade na estimativa de tempos produtivos e da melhor opção em termos de equipamento é muitas vezes deixada a especialistas da empresa (Henriques, Peças, 2003; Florjanič, Kuzman, 2012; Zawila, 2002). Esta decisão é ainda mais complexa quando estão em causa diversas tecnologias de fabrico como a fresagem (convencional, CNC a 3 eixos, CNC a 5 eixos, alta-velocidade), furação profunda, retificação, electro-erosão (por fio e de penetração), polimento, entre outras e ainda a montagem final do molde (em todas as empresas fabricantes de moldes coexistem estas tecnologias). É preciso um nível de conhecimento muito abrangente por parte do decisor que planeia a sequência de produção dos diversos componentes, sendo que é fundamental a existência de informação atualizada e precisa sobre o estado de produção de cada molde (Peças, 2012; Henriques et al., 2007). O terceiro fator está relacionado com as características de relacionamento com os clientes. Por um lado, o cumprimento do prazo de entrega negociado é um fator de diferenciação, por outro o molde tem de ser lançado à produção antes de as geometrias finais estarem estabilizadas por parte do cliente. Esta situação origina uma pressão enorme sobre as atividades de planeamento, que assim é obrigado, por razões exógenas, a alterar decisões anteriores de sequenciamento devido à necessidade de refazer um componente de um molde quase em fase de 
montagem (Henriques, Peças, 2003). O último fator é essencialmente interno e prende-se com problemas relacionados com 1) a comunicação ente a fase de design do molde e realização de programas de maquinagem e a fase de produção; 2) deficiente calibração das ferramentas de corte e 3) erros no fabrico do elétrodo. Estes aspetos podem originar a necessidade de um nível retrabalho significativo e longos tempos de espera e aumento do "lead time" do molde. Estes aspetos geram inequivocamente, mais uma vez, uma pressão significativa nas decisões de planeamento (Henriques, Peças, 2004; Henriques, Peças, 2003; Zawila, 2002).

A conjugação destes fatores leva a que as inúmeras aplicações informáticas desenvolvidas para apoio ao planeamento do fabrico de moldes respondam apenas a parte dos problemas com que os responsáveis de planeamento se debatem (Florjanič, Kuzman, 2012; Apostu, Bendul, 2015). Torna-se, portanto, comum as decisões de planeamento estarem centradas em um ou dois especialistas da empresa, com elevada experiência e conhecimento, que decidem com a informação disponível qual o melhor sequenciamento, qual o melhor equipamento e qual a prioridade de um dado componente. Refira-se que têm sido desenvolvidas por diversos investigadores, diversos modelos de otimização baseados em métodos heurísticos e métodos meta-heurísticos de predição e estimativa para vários estágios de produção (Wongwiwat et al., 2013; Florjanič, Kuzman, 2012; Apostu, Bendul, 2015). Dentro dos vários tipos de métodos existentes: intuitivos, analógicos, paramétricos e analíticos, os que de facto subsistem em utilização (de forma informal) são os intuitivos, apesar dos esforços dos investigadores e do mérito científico dos outros tipos de modelos (Wongwiwat et al., 2013; Florjanič, Kuzman, 2012; Apostu, Bendul, 2015).

Neste artigo propõe-se a utilização de um modelo do tipo intuitivo, o MPM, que tem como virtude aproveitar o elevado conhecimento e experiência dos especialistas da empresa na arte de planear.

O MPM - Mapeamento do Progresso dos Moldes "apenas" exige ao seu utilizador que indique a criticidade dos tipos de componentes do molde e a contribuição prevista das fases em que se divide o seu fabrico. Tem como alicerces a lógica da Gestão Visual possibilitando ao decisor ter, a cada momento, uma estimativa bastante fiável do nível de execução do molde e dos seus componentes. É aplicável num contexto de Indústria 4.0, assumindo-se a sensorização de todos os equipamentos e a existência na empresa da plataforma "internet-of-things" (rede informática virtual onde estão ligados todos os equipamentos). Desta forma irá permitir ao decisor planear de forma informada, consciente e flexível, uma vez que dispõe de informação atualizada e ponderada sobre criticidade e sobre importância específica de cada componente e de cada molde em geral.

\section{MATERIAIS E MÉTODOS - OS FUNDAMENTOS NA ORIGEM DO MPM}

A origem do MPM resulta da conjunção de 3 aspetos que coexistem simultaneamente: 1) o atual modelo de planeamento nas empresas fabricantes de moldes; 2) a consolidação e validação das boas práticas gerais de planeamento e gestão fundamentadas na filosofia de produção Lean (Lean Manufacturing), em particular a Gestão Visual; e 3) a tendência de evolução aditivada pela lógica Indústria 4.0.

Reforça-se que, o contexto de aplicação do MPM é o de ajudar as empresas fabricantes de moldes a responder às exigências e particularidades do seu tipo de planeamento: one-of-kind; baixa ou nula repetibilidade; explosão da encomenda em dezenas de componentes diferentes a fabricar; interferência permanente do cliente com alterações a componentes já em fabrico (Henriques, Peças, 2004; Henriques, Peças, 2003). 


\subsection{Modelo de planeamento em vigor}

O atual modelo típico de planeamento das empresas fabricantes de moldes está presente na Figura 1. Esta lógica foi definida tendo por base a análise de modelos a várias empresas que produzem moldes de elevada qualidade e fiabilidade. Pode-se então referir que em geral o modelo de planeamento atual está divido em duas grandes etapas. A primeira passa por enquadrar no plano de produção anual a adjudicação de um molde novo à empresa. É aqui que a empresa discute as datas dos primeiros ensaios e a data de entrega com o cliente. Posteriormente, define-se o período de produção (estimativa do número de semanas de produção). Por fím, caso a empresa esteja no limite da sua disponibilidade produtiva, o fabrico de componentes é adjudicado a empresas externas.

A segunda etapa é a definição do escalonamento diário e semanal da produção de componentes. Os responsáveis pelo planeamento, que definem à priori a sequência de fabrico dos componentes, consultam-na e consultam também a disponibilidade das máquinas no chão de fábrica, ou seja, máquina a máquina, para que posteriormente tomem uma decisão acerca de qual a prioridade dos componentes e qual a máquina em que os componentes vão dar entrada.

Estas decisões são tomadas no lançamento do molde (ou seja, dos seus componentes) à produção sem que haja um mecanismo para saber em que estado de evolução estão os moldes atualmente em produção. Este facto origina, tal como referido por um responsável de planeamento "o escalonamento diário ou semanal é um escalonamento bombeiro". Ou seja, quando o prazo de entrega de determinado molde se aproxima, os componentes desse molde passam a ter prioridade, e caso seja necessário, interrompe-se a produção dos componentes de outros moldes, para dar prioridade aos componentes desse molde, originando potencialmente esperas e retrabalho (Zawila, 2002).

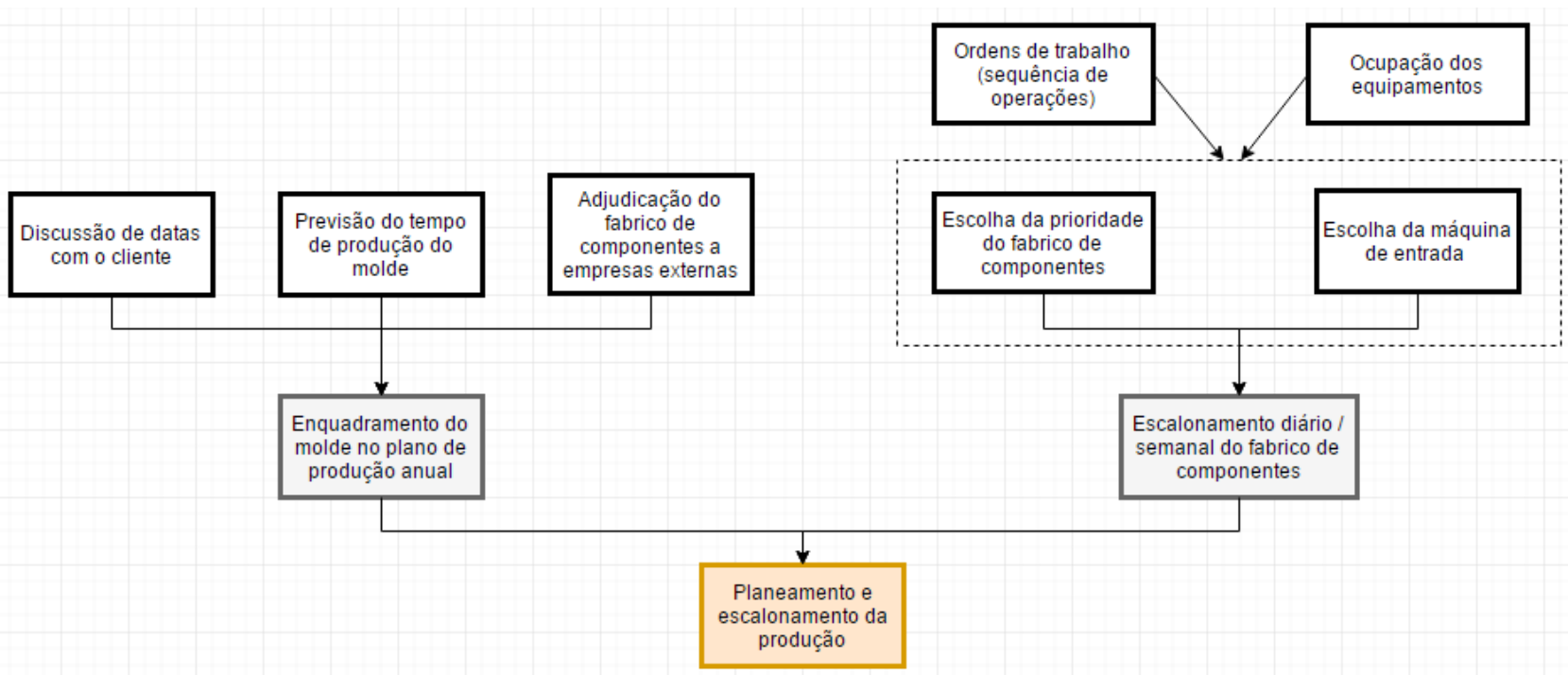

Figura 1 - Modelo de planeamento em vigor.

Para que se tenha noção das consequências deste modelo de planeamento "no escuro", ilustra-se aqui um caso particular de uma das empresas analisadas, mas que no fundo é representativo da maioria das empresas (Tabela 1). Apenas 23\% do "lead time produtivo" consiste em atividades de valor acrescentado, como atividades de maquinagem, ou atividades sem valor acrescentado mas necessárias como o controlo e o setup entre componentes.

O tempo restante é consumido em esperas. A Espera não laboral não foi considerada relevante, já que corresponde ao horário de almoço ou ao período noturno, no qual os operadores 
não se encontram a laborar. A Espera em horário laboral entre seções foi também considerada pouco relevante neste caso de estudo, já que num qualquer sistema produtivo, de forma mais ou menos intensa, é normal que quando um componente transita de uma secção para a seguinte, exista algum tempo de espera, que é causado pelos componentes que têm prioridade (FIFO).

Seguiu-se a análise ao Retrabalho e à Espera em horário laboral na mesma seção, entre máquinas. Estes dois factores estão diretamente relacionados, uma vez que a Espera contabiliza o tempo decorrido entre o fim da primeira maquinagem de um componente, até à re-introdução do componente nessa mesma máquina ou numa equivalente, representando assim um Retrabalho.

O valores de $3 \%$ de Retrabalho e de $32 \%$ de Espera, em relação ao Lead Time Produtivo, que foram considerados elevados e serviram de motivação para o estudo aprofundado das causas e desenvolvimento de uma solução que minizasse este dois desperdícios. De realçar, neste caso particular, a baixa incidência do retrabalho, no entanto, em algumas empresas este valor pode atingir $10 \%$ do lead time produtivo.

Tabela 1 - Resultados do diagnóstico na produção de cavidade, bucha e postiço.

\begin{tabular}{|c|c|c|}
\hline Principais causas & $\begin{array}{c}\text { Tempo } \\
\text { (h) }\end{array}$ & $\begin{array}{c}\text { Percentagem } \\
\text { de LTP }\end{array}$ \\
\hline Tempo Produtivo (valor acrescentado, setups e controlo) & 433 & $23 \%$ \\
\hline Retrabalho & 61 & $3 \%$ \\
\hline Esperas em horário laboral na mesma seção, entre máquinas & 592 & $32 \%$ \\
\hline Esperas em horário laboral entre seções & 401 & $22 \%$ \\
\hline Esperas em horário não laboral (horários não úteis como: horas de almoço, intervalos, horas não laborais, etc.) & 361 & $20 \%$ \\
\hline Lead Time Produtivo (LTP) & 1848 & $100 \%$ \\
\hline
\end{tabular}

As principais causas identificadas para estas as esperas e retrabalho foram a interrupção da produção de componentes por alteração das prioridades, a falta de elétrodos de electro-erosão porque não se anteviu a sua necessidade e a desadequação do programa de maquinagem devido à chegada tardia de informação de outra área da empresa. Esta situação deriva do planeamento sofrer alterações constantes e não existir uma permanente noção das prioridades e do estado efetivo de produção de cada molde e dos seus componentes.

Resulta claro, que a informação acerca do progresso dos moldes e das operações que ainda falta realizar, bem como a quantificação dos dias de atraso ou avanço que o molde tem em relação ao prazo estipulado com o cliente, seriam uma grande mais-valia no apoio à decisão do planeamento e escalonamento.

\subsection{Filosofia Produção Lean e boas práticas}

Descrevem-se de seguida as boas práticas de planeamento no fabrico de moldes que resultam de junção de várias fontes de informação e conhecimento, nomeadamente das lógicas e práticas da filosofia de produção Lean (Rother, Shook, 2009; Womack et al., 1990) e da compilação de opinião de especialistas do setor (Henriques, Peças, 2012; Henriques, Peças, 2003; Zawila, 2002), resultam: boas práticas organizacionais, operacionais, tecnológicas, colaborativas e de maximização do fluxo produtivo.

As boas práticas organizacionais têm por base um conhecimento (ou boa estimativa) dos prazos de entrega dos componentes comprados a fornecedores, da contribuição de cada componente do molde no processo de fabrico e das competências/características dos operadores e dos equipamentos. A especificidade das empresas fabricantes de moldes leva a que tenham no 
responsável pelo planeamento o elemento que domina estes aspetos, embora não possua uma plataforma onde possa depositar este conhecimento e torná-lo útil.

As boas práticas operacionais consistem na existência de procedimentos escritos e a sua adaptação a cada cliente e a cada molde. Esta situação evita a duplicação de trabalho previamente efetuado e reduz a probabilidade de erros. É, portanto, fundamental compreender a criticidade de cada molde e dos seus componentes, assim como conhecer o nível de cumprimento dos prazos de entrega, para cada caso. A definição destes aspetos numa fase anterior ao lançamento do molde à produção permitirá um planeamento mais eficaz na resposta ao mercado e uma gestão mais eficiente dos recursos e do tempo disponível.

As boas práticas tecnológicas envolvem um conhecimento acumulado e profundo das tecnologias existentes e de cada equipamento específico. Desta forma será possível dominar a adequação de um dado equipamento para a realização de uma dada operação de maquinagem. Permite ainda ter a sensibilidade para entender a criticidade da produção de certos componentes, a probabilidade de surgirem complicações e/ou minimizar as mesmas. Este conhecimento está normalmente centrado nos responsáveis de produção e de planeamento, que em conjunto deverão caracterizar estes aspetos numa fase prévia ao lançamento em produção (Zawila, 2002), embora em geral não exista uma plataforma onde possam registar essa informação.

Em sequência deste último aspeto surgem as boas práticas colaborativas entre elementos de vários setores (programação, planeamento e produção) que juntos tomarão decisões mais fiáveis e robustas (Henriques, Peças, 2004; Henriques, Peças, 2003). Mais uma vez, sendo uma prática recomendável, não existe disponível uma plataforma onde essa informação e decisões possam ficar plasmadas para cada molde e seus componentes.

Por fim, as boas práticas de maximização do fluxo que preconizam a minimização das esperas através da priorização dos componentes mais avançados na produção (Zawila, 2002; Rother, Shook, 2009). Apesar dos decisores poderem ter conhecimento destas boas práticas, a falta de noção do progresso de cada componente e de cada molde no global pode turvar a visão e levar a decisões que não se revelam as melhores. Este ponto é "solucionado" pela adoção da Gestão Visual.

De forma resumida, a Gestão Visual tornou-se um dos aspetos cruciais para o sucesso da filosofia de produção Lean (Womack et al., 1990; Galsworth, 2013). Trata-se de uma técnica de disponibilização da informação, a qual é comunicada através de sinais visuais intuitivos, no lugar de longos textos e informação excessiva. Pretende-se melhorar a eficácia da comunicação, tentando obter um processamento da informação mais rápido, mais claro e eficiente. A gestão visual engloba também a obtenção de locais de trabalho limpos e organizados de forma a, no caso de haver algum erro ou situação fora do comum, esta ser facilmente identificável e controlável, sendo possível uma maior clareza do processo e do desempenho da organização (Galsworth, 2013; Wrye, 2016; Imai, 1997). Tendo por objetivo global garantir que o espaço fabril é auto-regulado, auto-melhorado, auto-organizado e auto-explicado (Galsworth, 2013; Wrye, 2016), é este último que é mais óbvio para o apoio às decisões de planeamento: disponibilizar ao utilizador informação completa sobre o progresso dos vários moldes para que ele possa de forma intuitiva e ágil ficar a conhecer o estado do sistema.

O MPM utiliza estas lógicas e ferramentas com o objetivo de potenciar decisões intuitivas baseadas na experiência e conhecimento do decisor, mas fornecendo-lhe um mapeamento completo e atualizado do progresso de cada componente e do molde. Irá permitir ao decisor incorporar numa só ferramenta o seu conhecimento e experiência relativa à importância ou contributo de cada fase de produção do molde e à criticidade dos principais componentes. Estes conceitos são explicados em detalhe na próxima secção relacionada com o MPM. O MPM permite ainda incorporar 
conhecimento e experiência de outros atores nas decisões de planeamento: a montante os elementos da programação da maquinagem de elétrodos e de componentes, e a jusante os elementos da produção com os seus conhecimentos específicos sobre cada processo e cada equipamento. Esta integração de informação é efetuada numa fase preliminar à produção permitindo decisões de planeamento mais informadas e atualizadas e certamente mais eficazes e promotoras de eficiência do sistema produtivo.

\subsection{Indústria 4.0}

Não se pretende neste artigo tecer grandes considerações sobre a evolução dos sistemas produtivos correntes (sistemas maioritariamente físicos) para os sistemas produtivos ciber-físicos, seguindo a tendência da denominada $4^{a}$ revolução industrial ou Indústria 4.0 (Dujin et al., 2014). É um facto que todas as empresas de transformação num futuro próximo vão ter os seus equipamentos munidos de sensores e outros meios de recolha de dados de vários tipos. Vão também estar equipadas com aplicações informáticas que lhes permitem ter uma rede de dados onde estará disponível a quase totalidade da informação sobre as tarefas que cada equipamento e operador estão a realizar (internet-of-things). No entanto, a disponibilidade desta informação a vulso sem qualquer tratamento e hierarquia de análise tornará a gestão caótica e ainda mais complexa do que a que atualmente existente (Dujin et al., 2014). Sendo este, o contexto em que se preconiza que o MPM funcione, as suas características permitirão exatamente aproveitar esta informação, tratá-la de forma estruturada e devolver ao utilizador informação simples, concisa e atualizada para poder decidir de forma informada e atualizada (em tempo real).

Fica então claro que o MPM tirará partido desta potencialidade emergente, utilizará lógicas de produção Lean e de Gestão Visual, não alterando na substância os modelos de planeamento atualmente instalados. Pelo contrário, permitirá ao utilizador usar a sua inteligência, experiência e conhecimentos únicos para decidir, mas tendo uma visão periférica do progresso de cada molde.

\section{RESULTADOS E DISCUSSÃO - MPM (Mapeamento do Progresso dos Moldes)}

Mapeamento do progresso de moldes, ou MPM, foi o nome dado ao método desenvolvido como solução, que pretende responder às lacunas de informação identificadas, na tomada de decisão de planeamento e escalonamento da produção de moldes. O método tem o objetivo de dar a conhecer, em tempo real, o estado da produção dos moldes, permitir o cálculo do desvio potencial de dias em relação ao prazo definido com o cliente e permitir a definição de marcos temporais na produção de um molde. Com este mapeamento, os responsáveis de produção e planeamento terão maior facilidade em acomodar novos moldes no planeamento anual, poderão identificar as prioridades de forma atempada e fazer um planeamento semanal de produção detalhado, tendo em conta o progresso real dos mesmos.

Este método só é possível com a integração de um software de identificação informática (SII) dos componentes, que registe as operações e os tempos de fabrico respetivos que os componentes já realizaram. O MPM foi pensado admitindo que este SII existe e que é bem alimentado.

O mapeamento do progresso de moldes proposto está representado de forma esquemática na Figura 2. Após a introdução da sequência de operações, são introduzidos inputs de nível de criticidade das categorias de componentes e dos contributos relativos (pesos) de cada fase ou tipo de operação necessários para o seu fabrico. São ainda introduzidas as datas de início e saída do molde (desejável) e marcos temporais para cada fase da produção. 
Após a entrada à produção o SII vai informando o MPM acerca da posição em que cada componente está, sendo "apenas" importante para o MPM saber que etapas da produção é que cada componente já concluiu. Através da utilização dos valores de criticidade e pesos de contribuição o MPM informa o utilizador sobre: marcos temporais não cumpridos e o seu nível de criticidade, o progresso geral do molde e dos componentes e o desvio potencial de avanço ou atraso em relação às datas limite estipuladas. O ciclo é complementado com a realização de reuniões periódicas de afinação dos inputs do MPM.

Desta forma, e efetuando este ciclo para todos os moldes que entram à produção, a informação é disponibilizada pelo MPM, ou seja, existe um mapeamento do progresso dos moldes. O responsável pelo planeamento e outros decisores, ficam a saber o estado atual da produção, tornase possível o reajuste informado do escalonamento e do planeamento de produção, através da realização de reuniões, que deverão ser diárias.

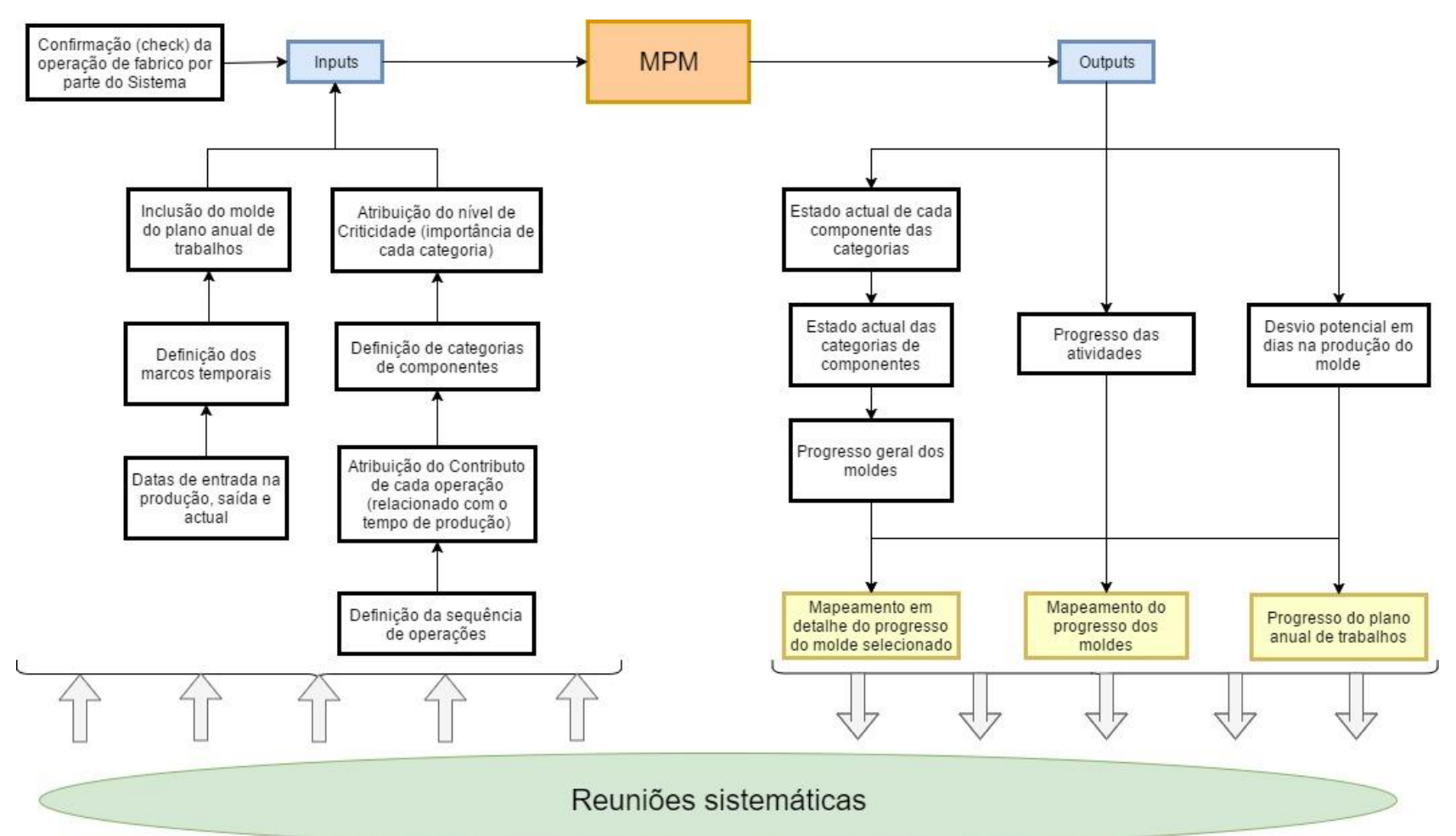

Figura 2 - Esquema representativo do funcionamento do MPM.

O primeiro input é a definição da sequência de operações que cada componente (ou conjuntos de componentes, que constituem um molde) terá de ser sujeito para atingir a sua configuração final. Após este input terá de ser definido para cada operação um peso em percentagem (Contributo de cada fase), cujo valor é definido em função de uma estimativa da distribuição do tempo de produção, que cada operação ou conjunto de operações representa. A ideia é utilizar a experiência dos elementos ligados ao planeamento e produção para atribuir uma carga percentual (pesos). Na Figura 3 está representada a sequência típica de operações mais comum à maioria dos componentes. A sequência deverá ser adaptada a cada componente, mas será comum à maioria deles para um dado molde.

À medida que cada componente vai avançando na sequência de fabrico, as percentagens (pesos) das operações vão sendo somadas no progresso do componente. Ou seja, assim que 
determinado componente tiver terminado uma operação, o SII envia informação para o MPM, indicando que aquela operação está concluída, aumentando, consequentemente, o progresso do componente com o peso que corresponde à operação. Finalmente, este progresso é somado no progresso de cada categoria de componentes do molde.

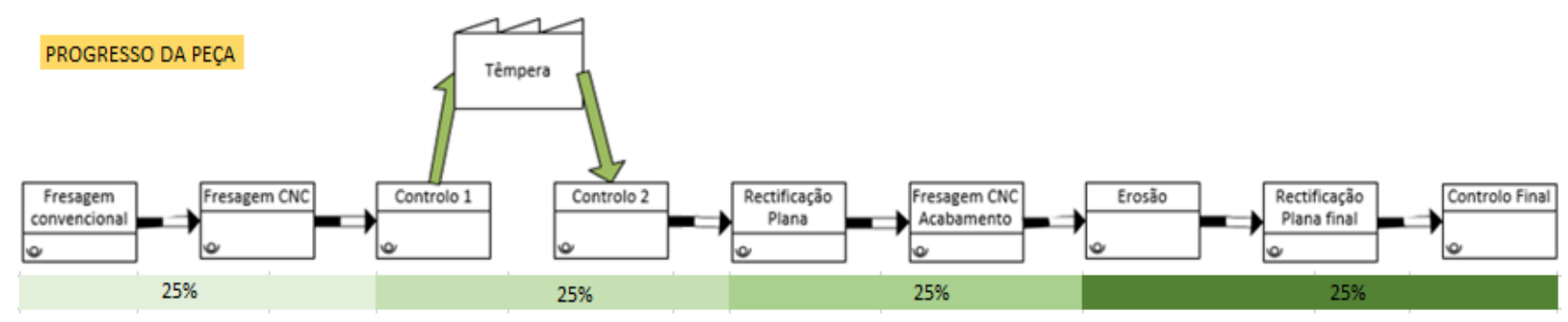

Figura 3 - Sequência de operações e pesos relativos ao Contributo.

Segue-se o agrupamento dos componentes em categorias, sugerindo o MPM a divisão em 6 (Figura 4):

Categoria 1 - Bucha, cavidade, postiços e elétrodos;

Categoria 2 - Elementos móveis;

Categoria 3 - Elementos estruturais;

Categoria 4 - Outros componentes;

Categoria 5 - Componentes externos;

Categoria 6 - Bancada (primeira montagem do molde).

À semelhança da sequência de operações, também nas categorias é necessária a atribuição de pesos. Desta vez, os pesos baseiam-se na Criticidade que depende subjetivamente de vários fatores como o risco de insucesso (complexidade), a importância no molde, impacto no cliente, etc. Estes pesos devem ser atribuídos mais uma vez pelos decisores com base na sua intuição, experiência e conhecimento. Os pesos presentes na Figura 4 são exemplificativos embora representem uma situação típica.

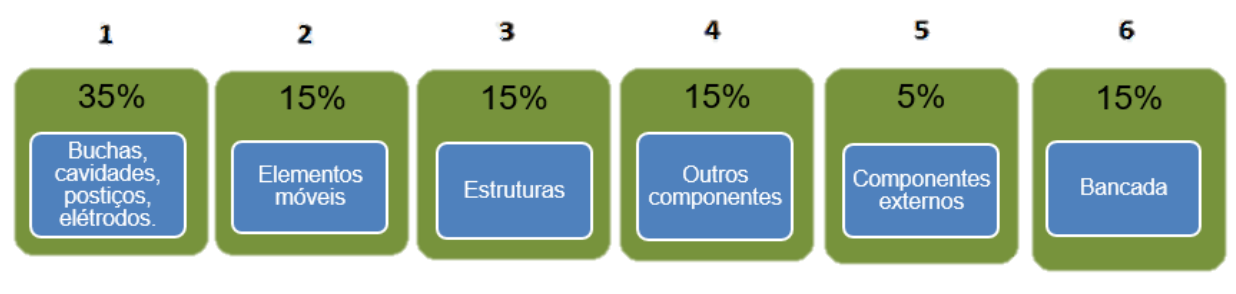

Figura 4 - Categorias de componentes e os respetivos pesos relativos à Criticidade.

O progresso do molde resulta da conjunção entre os pesos do Contributo de cada fase, os pesos da Criticidade de cada categoria e da informação em tempo real que vem do SII. Com base nestas informações, o MPM informa ainda o utilizador sobre o desvio potencial de atraso ou avanço na produção dos moldes. 
Com o intuito de seguir a lógica apresentada até então, de responder às lacunas anteriormente identificadas e ainda, de forma a ter uma maior eficácia interventiva, propõe-se que o MPM tenha dashboards, que serão apresentados desde uma análise detalhada por componente, passando pelo progresso geral dos moldes e terminando no plano anual de trabalhos da empresa. Para facilitar a gestão visual, os dashboards possuem vários alertas que consoante a cor, indicam um nível de criticidade do progresso ou do desvio diferente (Figura 5).

$\begin{array}{lllll}\text { Legenda progresso }[0 \%] & {[11 \%-49 \%]} & {[50 \%-90 \%]} & {[90 \%-99 \%]} & {[100 \%]} \\ \text { Legenda Desvio } & \text { Atraso } & \text { Sem atraso Avanço } & \text { Avanço }>5 \text { dias }\end{array}$

Figura 5 - Legenda do progresso e do desvio temporal nos dashboards.

No primeiro dashboard, a que se deu o nome de mapa do progresso dos moldes (Figura 6), é compilada toda a informação referente à produção dos moldes. É um mapeamento em detalhe de cada molde, que explana o progresso de fabrico das dezenas de componentes que os constituem. Pretende-se que este dashboard permita ao utilizador:

1. Analisar num mapa geral o progresso produtivo dos moldes que estão em fabrico;

2. Particularizar a análise feita a um molde selecionado, em que seja apresentado, ao detalhe, o progresso dos seus constituintes.

Com estas duas funcionalidades, prevê-se que os responsáveis da produção e planeamento consigam tomar decisões estratégicas, tendo previamente analisado o estado geral da produção, e particularizando o seu saber, nos moldes que mais se realçam no MPM.

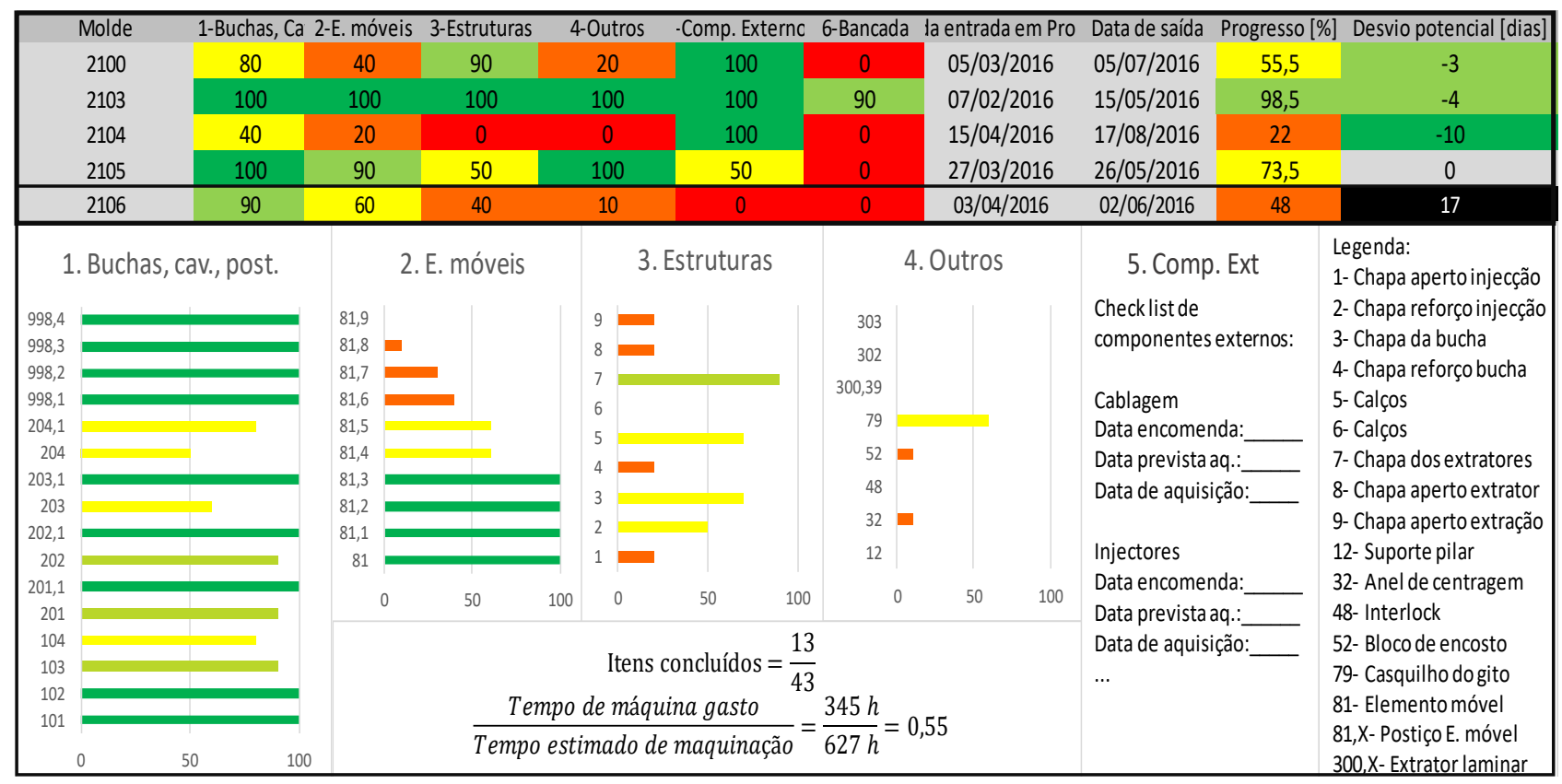

Figura 6 - Mapa do Progresso dos Moldes. Retângulo superior: mapa geral do progresso dos moldes; Retângulo inferior: Mapa pormenorizado do molde selecionado (2106).

Na Figura 6 está representada uma sugestão de apresentação do dashboard principal do MPM. No retângulo superior, do lado esquerdo, estão enumerados os vários moldes em produção, 
seguido dos progressos (em percentagem) das várias categorias, bem como o alerta colorido indicando o nível de criticidade. Nas duas colunas, a cinzento, são apontadas as datas de entrada e de saída da produção. Por fim, na penúltima e na última coluna são identificados, respetivamente, o progresso e o desvio potencial atualizados para cada molde em produção na empresa.

O progresso dos moldes é expresso à semelhança dos restantes indicadores do progresso, em percentagem e com um alerta de criticidade colorido. Já o desvio potencial é apresentado em dias e um valor positivo, como o caso do molde 2106, que indica 17 dias, significa que a produção já está atrasada 17 dias, em relação à data de saída. Um valor negativo, como por exemplo, o valor do desvio potencial do molde 2100, mostra que o molde está adiantado 3 dias em relação à data de saída.

O retângulo superior sugerido no dashboard da Figura 6 representa de forma macro o progresso de todos os moldes, que a empresa tem atualmente em produção. No entanto, esta informação não é suficiente para perceber, se por exemplo, o molde 2106 tem a segunda categoria a $60 \%$ porque todos os elementos móveis estão a $60 \%$ (imaginemos que são dez), ou porque tem seis elementos concluídos, a 100\%, e os outros quatro ainda não iniciaram as operações de fabrico.

Foi então essencial ponderar qual seria a melhor forma de apresentar pormenorizadamente o progresso de cada categoria, categorias estas que contribuem para o estado atual do molde. Assim, quando os responsáveis pelo planeamento e produção estiverem interessados em perceber melhor qual a razão do progresso de determinado molde, basta que selecionem o molde em questão, e a informação do progresso das dezenas de componentes desse molde é apresentada no dashboard (retângulo inferior da Figura 6). O progresso de cada categoria (numeradas de 1 a 5) é detalhado pelos diversos progressos dos componentes que as constituem sob a forma de gráficos barras, numa escala de 0 a $100 \%$, com a correspondência de alertas de Criticidade coloridos. Os componentes foram numerados para facilitar a representação gráfica e existe, por isso, uma legenda para esta numeração, que se encontra à direita na figura.

Este dashboard pormenorizado do MPM expõe ainda rácio de itens concluídos em relação ao número total de componentes do molde. No exemplo da Figura 6, o molde selecionado foi o molde 2106 e é possível concluir que dos 43 componentes que o molde possuí 13 já estão concluídos.

Por fim, este dashboard apresenta também o rácio entre o tempo de máquina realmente gasto e o tempo total de maquinação estimado na fase de planeamento. No molde 2106, dado como exemplo na Figura 6, o rácio entre horas gastas e horas estimadas corresponde a 55\% do total do molde. No entanto, o MPM indica que o progresso atual do molde é de $48 \%$ o que revela a subvalorização das horas totais estimadas. Este método permite assim, que com base nestes valores, os responsáveis pela produção, planeamento e orçamentação comparem e estimem o número de horas de maquinagem real consumidos e reflitam sobre essa informação para orçamentação e controlo de futuros moldes.

A categoria 5 salienta a data de encomenda, a data prevista de chegada da encomenda e a data de aquisição de componentes comprados externamente.

Salienta-se que na categoria 6 - Bancada - que corresponde a um só processo, a existência de um gráfico de barras é desnecessário, pelo que o seu progresso está apenas presente na linha geral do molde no MPM.

De forma a consolidar a informação anterior, com este dashboard é possível entender que o progresso dos componentes nas fases de fabrico que lhe estão atribuídas dão um Contributo ao progresso das categorias. Por sua vez, o progresso das categorias atribui um peso/Criticidade ao 
molde, e é o conjunto destes progressos que permite calcular o progresso geral e o desvio potencial do fabrico do molde.

O MPM preconiza igualmente a definição de marcos temporais na produção, precisamente para prevenir que o desvio potencial atinja valores indesejáveis.

Portanto, especificou-se um dashboard que apresenta a acomodação dos moldes no Gantt anual de trabalhos e que exibe as várias fases dos trabalhos e os correspondentes marcos temporais (Figura 7).

Com a definição destas metas a atingir em datas estipuladas, minimizam-se as probabilidades de uma entrega de produto atrasada ao cliente, ou de um avanço na produção, que por vezes também não é desejável, já que se pode estar a penalizar outra produção em prol deste avanço.

Para esta solução, os responsáveis pelo planeamento e pela produção devem definir quatro marcos, ou seja, as datas limite das operações:

1. Data da aquisição da matéria-prima;

2. Data do progresso do projeto (CAD), a partir do qual a produção pode arrancar;

3. Data fim da produção do molde (inclui primeira montagem);

4. Data fim da fase de testes e consequente montagem final (corresponde à data de entrega ao cliente).

$\mathrm{Na}$ Figura 7, são apresentados os esquemas visuais da definição dos marcos temporais para três moldes, o molde 2105, o 2106 e o molde 2107. Os marcos temporais estão assinalados pelas barras vermelhas e as datas correspondentes imediatamente ao lado.

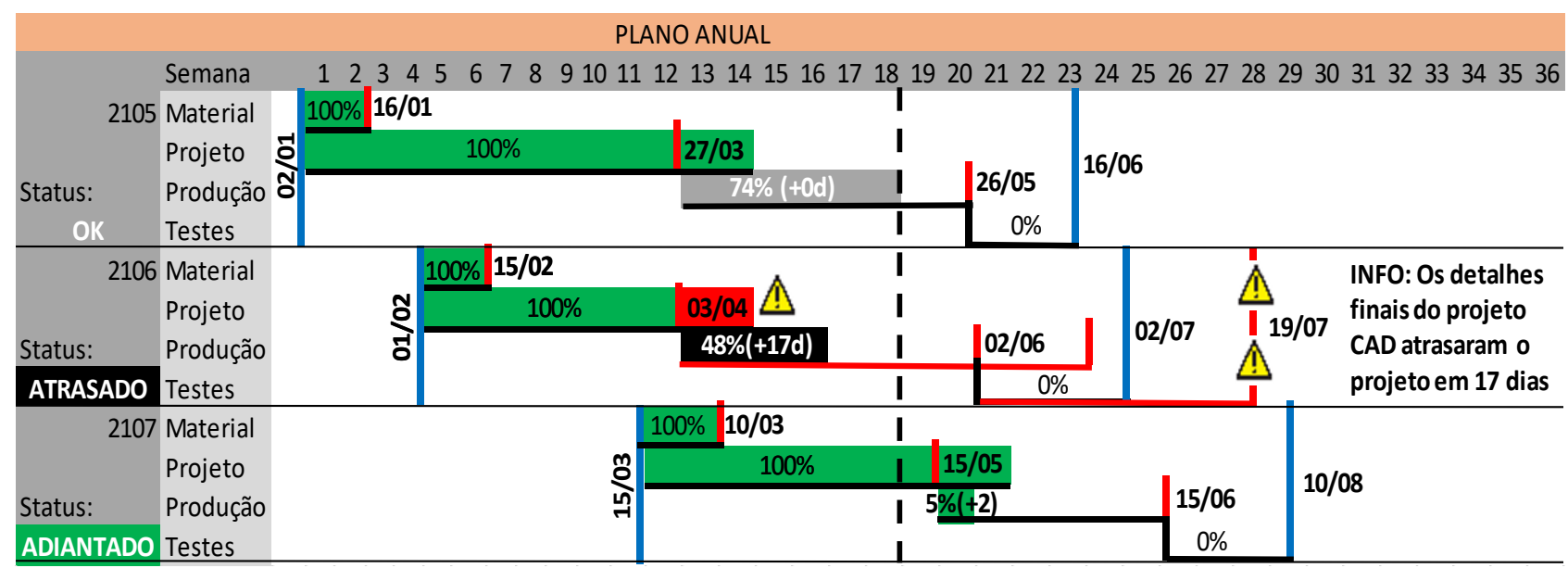

Figura 7 - Dashboard de progresso do plano anual de trabalhos.

O progresso visual das fases de Material, Projeto e Testes evolui linearmente em função do tempo que foi estabelecido para cada uma, e para cada molde, a menos que seja diretamente inserido no MPM por quem compete essa determinada função. A barra da Produção, pelo contrário, é extraída diretamente do dashboard anterior do MPM, e varia consoante o progresso do fabrico.

Como se pode observar na Figura 7, no molde 2105, o mesmo molde 2105 da Figura 6, o progresso da atividades está a correr, em geral, de forma controlada, não há atrasos, nem avisos, e por isso o Status OK é emitido do lado esquerdo (por baixo da designação do molde). Pelo contrário, por exemplo no molde 2106, o projeto CAD teve um atraso de 17 dias. Como tal, a 
produção e a fase de testes estão igualmente atrasadas. O atraso é realçado por uma barra que se estende até ao prazo previsto de entrega, tendo em conta o atraso e por vários sinais de perigo, e é atribuído o Status de ATRASADO ao molde. É ainda emitida uma nota, de preenchimento obrigatório, que informa o utilizador da razão pela qual o atraso surgiu.

No caso do molde 2107, o Projeto CAD terminou antes do tempo. Pode ou não ser emitida uma nota informativa que identifique a razão do adiantamento. Neste caso, é emitido o Status de ADIANTADO.

\section{CONCLUSÃO}

O MPM propõe uma abordagem visual e compreensiva do estado de progresso dos diferentes moldes em produção numa empresa. Tem por objetivo apoiar os decisores de planeamento na difícil tarefa de "encaixar" centenas de componentes em produção em dezenas de equipamentos, garantindo a satisfação do cliente e em simultâneo a minimização de desperdício de tempo e de recursos.

O sucesso e viabilidade do MPM e do cumprimento dos marcos temporais, para o apoio à decisão de planeamento, só será alcançado com a realização de reuniões sistemáticas de análise aos métodos, permitindo aos responsáveis tomar decisões informadas no refinamento da produção de componentes, na adjudicação de novos moldes no plano anual, tendo sempre em conta o progresso real de toda a produção de moldes da empresa. Estes métodos apresentados são ainda fundamentais na deteção de possíveis origens de desperdícios e no posterior desenvolvimento de soluções, preconizando a sua eliminação.

Com o MPM torna-se possível visualizar o progresso de cada molde tendo em conta a sua complexidade específica e progresso dos vários componentes, calculando o desvio potencial do prazo de entrega do produto ao cliente. O MPM poderá também ser aplicável também noutras produções de elevada complexidade produtiva e baixa repetibilidade.

\section{REFERÊNCIAS}

APOSTU, M.V., BENDUL, J. Long-term capacity planning in die manufacturing using the estimated product cost: an exploratory research. 48th CIRP Conference on MANUFACTURING SYSTEMS - CIRP CMC 2015, Ischia (Nápoles), Italia, 2015.

DUJIN, A., GEISSLER,C., HORSTKOTTERR, D. INDUSTRY 4.0, The new industrial revolution - How Europe will succeed. Think-Act, Roland Berger SC, 2014.

FLORJANIČ, B., KUZMAN, K. Estimation of Time for Manufacturing of Injection Moulds Using Artificial Neural Networks-based Model, POLIMERI, 33:1, 12-21, 2012.

GALSWORTH, G. D., Visual Workplace - Visual Thinking, Visual-Lean Enterprise Press, 2013.

HENRIQUES, E., PEÇAS, P., CUNHA, P. Perspectives of Mould Making Industry for Global Digital Manufacturing. Digital Enterprise Technologies - Perspectives and Future Challenges, P. Cunha, F. Maropoulos (Eds.), Springer, p. 449-456, 2007.

HENRIQUES, E., PEÇAS, P. The Need for Agile Manufacturing Implementation in Mould Making Business. Business Excellence, 2003.

HENRIQUES, E. PEÇAS, P. Organizational and Manufacturing Best-Practices to Improve Mould Making Competitiveness. RPD, 2004.

HENRIQUES, E., PEÇAS, P. New Business Models for the Tooling Industry. Advances in Business and Management, ed. Nelson, W.D., Nova Science Publishers, New York, 2012. 
IMAI, M. Gemba Kaizen, McGraw-Hill, 1997.

PLASTICSEUROPE, Plastics - the Facts 2015 - An analysis of European plastics production, demand and waste data, 2015.

ROTHER, M., SHOOK, J. Learning to See: Value Stream Mapping to Add Value and Eliminate Muda. The Lean Enterprise Institute, Inc., 2009.

WEF, The World Economic Forum. The New Plastics Economy: Rethinking the future of plastics, 2016.

WOMACK, J.P., JONES, D.T., ROSS, D. The machine that changed the world, New York: Macmillan Publishing Company, 1990.

WONGWIWAT, Asawin; BOHEZ, Erik LJ; PISUCHPEN, Roongrat. Production scheduling for injection molding manufacture using Petri Net model. Assembly Automation, v. 33, n. 3, p. 282-293, 2013.

WRYE, M. Visual Management is Critical to Lean, Beyond Lean, 2016 [Online]. Available: https://beyondlean.wordpress.com. [Acedido em 201704 13].

ZAWILA, J. Avoid bad planning. Moldmaking Technology Magazine, 1/1/2002, 2002. 